\title{
Materials Liaisons: facilitating communication in design- driven material innovation (DDMI) projects
}

In an increasingly complex 'problem' landscape, interdisciplinary collaboration is becoming an important part of design practice. Yet designers use very different language and methods to other disciplines, which can be a significant barrier to communication, shared understanding and trust. New methods to enable effective communication between designers and other disciplines are needed across the design industry. This paper presents research from an EU H2O2O funded project which is trialling a new Design-Driven Material Innovation (DDMI) methodology. The collaborative process, involving designers, scientists and manufacturers, presents a number of challenges, particularly in enabling people with very different disciplinary/national/cultural languages to understand one another. For the project to move forward, at the very least, designers need to understand the material's potential and scientists need to understand what designers want the material to 'be like'. Effective 'materials communication' is crucial. The study focusses on one approach - appointing 'materials liaison officers' - to facilitate the interdisciplinary exchange of materials information at a crucial stage in the project, when the first materials prototypes were being developed in response to design concepts. Drawing on interviews and workshop material the author discusses the benefits and limitations of using a 'bilingual' liaison to translate material understanding from one discipline to another. The findings highlight a number of aspects that affect interdisciplinary materials communication such as familiarity with the material type being developed, the number of processes involved in production of the material, the approach of the designer, and the role of materials samples as boundary objects to anchor the dialogue. There are implications for interdisciplinary design projects more generally, where communication is equally challenging and important.

Design-Driven Material Innovation; materials communication; interdisciplinary collaboration; facilitation

\section{Introduction}

Design is increasingly being recognised as an important catalyst at various stages of the product development process, rather than the conventional 'product design' stage. Design-driven materials innovation (DDMI) for example, involves bringing designers into the process at the beginning of the 
material's development to help guide the scientific enquiry towards an innovation which is desired by design and therefore considered more marketable.

The research presented in this paper is part of a DDMI project where the aim is to develop a 'circular' fibre for textiles, composites and plastics; one which is both made from waste materials and can also be made into new material after the use phase.

The current project involves 18 partner organisations from 10 countries, comprising textile and industrial designers, design researchers, a materials consultancy, materials scientists, social scientists, manufacturers and life cycle scientists. The main collaborative effort takes place during twelve two-day workshops, over $3 \frac{1}{2}$ years.

DDMI projects present a particular communication challenge. People with very different disciplinary/national/cultural languages need to understand one another, when their worldviews, working practices and vocabulary are likely to be very different. The project glossary, compiled by the author with input from project participants, demonstrates the very basic level at which misunderstandings were frequently occurring during the first few workshops. Technical terms such as 'fibre', 'filament', and 'spinning'; scientific terms such as 'hydrophobic' and 'titer', and terms where meaning varied between disciplines, such as 'scenario' and 'prototype', reveal a complex combination of communication barriers. Introducing a glossary was one simple way of deciphering and clarifying these nuances in language. Anecdotally, this intervention appeared to draw attention to misunderstandings and participants became more conscious of their language, more often explaining the terminology they were using.

Moreover, it became apparent that for DDMI projects, it isn't sufficient for designers to understand the material's potential and scientists to understand what designers want the material to 'be like'. For the collaboration to work communication must also build trust in what is being asked or said.

The study presented here looks at one method used in the project to address these communication barriers. It focusses on the activities of 'materials liaison officers' (MLOs) - four individuals who were appointed as intermediaries at a specific point in the project - the development of the first prototype - where effective materials communication was crucial. Their activities and the different approaches and methods they used are analysed to understand the potential and the limitations of appointing liaisons to facilitate communication about materials characteristics in projects of this type. The implications beyond the current project will then be considered.

\section{Context}

One of the main outcomes of the EU project will be a DDMI methodology 'model' to build theory in this emerging area. However, the main focus of this study is not the Design-Driven methodology but the methods used within the project to support the interdisciplinary communication about materials and therefore this will be the focus of the contextual review.

\section{Materials communication resources}

Rapid developments in the material sciences in recent years has resulted in the introduction of numerous new materials, broadening the selection available to designers. Yet, as has been acknowledged by others (Author 2010; Ashby \& Johnson 2002; Manzini 1986), designers often do not have the specific technical knowledge needed to understand how these new materials can meet the needs of their designs.

Resources to enable designers to understand the potential of new or unfamiliar materials have been developed. These include materials databases, sample collections, materials information and comparison software, yet several studies of designers' materials sourcing behaviour found that these are rarely used (Author 2010; van Kesteren 2008; Pedgley 1999; Karana 2004). Without exception these authors concur that for designers to understand materials characteristics they need 
to touch physical samples or at the very least see images of the materials as opposed to property data.

Wilkes et al (2015) propose 'isometric sample sets' in their paper "Design tools for interdisciplinary translation of material experiences", which is presented as a tool for use in DDMI. The authors suggest that providing collaborators with various different materials of the same shape and size provides a common reference point for discussions about materials characteristics. For example, a designer could say 'I need the material to be shinier than this sample' and the scientist can then better determine the desired characteristics to aim for in their development work. Likewise, a scientist could explain the concept of 'tenacity' by showing the designer two opposing samples. This is seen as a way of facilitating a dialogue about the senseoaesthetic characteristics of materials with varying physical (quantifiable) properties between people with very different cultural/disciplinary languages. This approach was then applied by the authors to the Light Touch Matters online course (Institute of Making 2017), which demonstrates how a discussion between a designers and a scientist with a materials focus could prepare them for developing materials together in a DDMI context.

\section{Understanding materials through dialogue with 'an expert'}

The approach of Wilkes et al, focussing on methods that support dialogue about materials, echoes the findings of the author's previous study that designers prefer to talk to 'someone who knows' about materials when trying to find an alternative solution (Author 2010). This person must be able to understand the material's potential and translate this into benefits for design. Described as 'materials translators', these individuals were found to be frequently associated with a materials sample collection and have design training (Author 2013).

This dialogue can then be supported by 'boundary objects' such as images and materials samples, as advocated by Wilkes et al (2016) after Star \& Griesemer (1989). However, the focus is on the people involved in the translation rather than the samples or tools themselves which serve a supporting role. In turn this places particular importance on 'human factors' such as the compatibility of skills and knowledge of the people involved, their background, ability and approach to collaboration - as Rieple et al (2005) acknowledge much of the skill in boundary-spanning is based on relationship building, trust and rapport as much as ability to speak different languages.

In light of this previous research, the current EU project represented an opportunity for the author to study materials communication in practice within a live interdisciplinary DDMI project. The stance was to observe how people communicated about materials with the particular aim of identifying individuals who were acting as 'materials translators' as well as building further knowledge around the role of boundary objects such as material samples. In actuality, this occurred in a more explicit way than had been anticipated, as the project methodology team decided to appoint people to this role when the need arose. 'Materials liaison officers' (MLOs) were identified to oversee communication at a particular point in the project which presented a unique opportunity to study this phenomenon in more depth.

\section{Method}

The study focusses on a specific period of the project, where the first materials prototypes were developed in response to design requirements. This is seen as a pivotal moment in the 'design-led' material development, where materials information exchange was of particular importance and therefore strategies to support the communication were devised and put into practice. Five individuals were assigned the role of MLO by the project methodology team. Their role was to communicate materials requirements from the designers to the material developers, who would then produce prototypes. 
The research sought to reveal the context and function of the ML process by interviewing the MLOs on aspects considered relevant to understanding the role, its successes and limitations. Each interviewee has been given a codename identified in figure 1 . The questions related to three main areas of interest:

- Previous experience

- ML process: from workshop 05 to workshop 06

- Effectiveness of tools and methods used

The project is facilitated through a series of twelve two-day workshops held every two to three months. This paper focusses on what happened during, and in between, workshop 05 and workshop 06 where designers were, for the first time, developing early-stage design concepts and needed to provide information to material developers about the characteristics of the first material prototypes to be produced in the project.

The data collected and analysed comprises transcripts from interviews conducted shortly after workshop 06 with four of the MLOs, as well as common discussions recorded during workshops 05 and 06 about material prototyping, and field notes. As the study focused on only a small section of the materials development process, the intention is to gather more data towards the end of the project to understand how this specific phase related to the project as a whole. The interviews were transcribed and coded by predetermined themes derived from the literature, existing research, field notes and the author's previous research.

The investigation had a dual purpose. First to understand whether the materials communication had been successful between workshops 05 and 06 and to highlight areas that could be improved in the convention of action research. Second, to understand the roles and actions being observed and relate these to the wider context of materials communication discussed earlier, to contribute to the growing body of knowledge about materials communication beyond the immediate project.

It is important to acknowledge that although the author/researcher did not instigate the ML process, they were part of the project methodology team. The data was collected as far as possible by stepping aside from the process. However the dual role of the research as both action and investigative (and consequently the dual role of the author/researcher) must be acknowledged and taken into account.

\section{Materials Liaison Officer role}

DDMI is not well established or understood, particularly in a large consortium project. Therefore, the project plan was experimental in nature, with opportunities to adapt and react to the challenges faced at each stage. These adjustments were considered and implemented by the project methodology team. At the point at which materials developers needed direction from the designers in order to meet deadlines for producing material prototypes (between workshop 05 and 06) the methodology team appointed materials liaison officers (MLOs) to facilitate this exchange in materials information. The lead facilitator for the communication amongst collaborators (also an MLO) explained in the interview how the need for a named liaison was identified:

I realised that there was no one who could convey the design request to the prototypist, So I said, okay, it's necessary that there are representatives from the design field [...] and maybe it's necessary to propose the creation of this representative that is the liaison officer, and also from the other side, the feasibility side or the technological side. [Des-B]

There were two levels of MLOs; two representing design, and two representing technical materials developers. Figure 1 shows the communication links between the MLOs, the designers and the technical materials R\&D for the two materials being developed in the project.

MLOs were appointed based on their position within the project and their perceived ability to perform the task. They were given a general briefing on the role and full autonomy on how they 
chose to work. This provides an interesting basis for comparison of methods as there was very little opportunity for cross-fertilisation of ideas and experiences between liaison officers. To the author's knowledge the liaison role had not been discussed at all prior to the interviews taking place, apart from at the initial briefing.

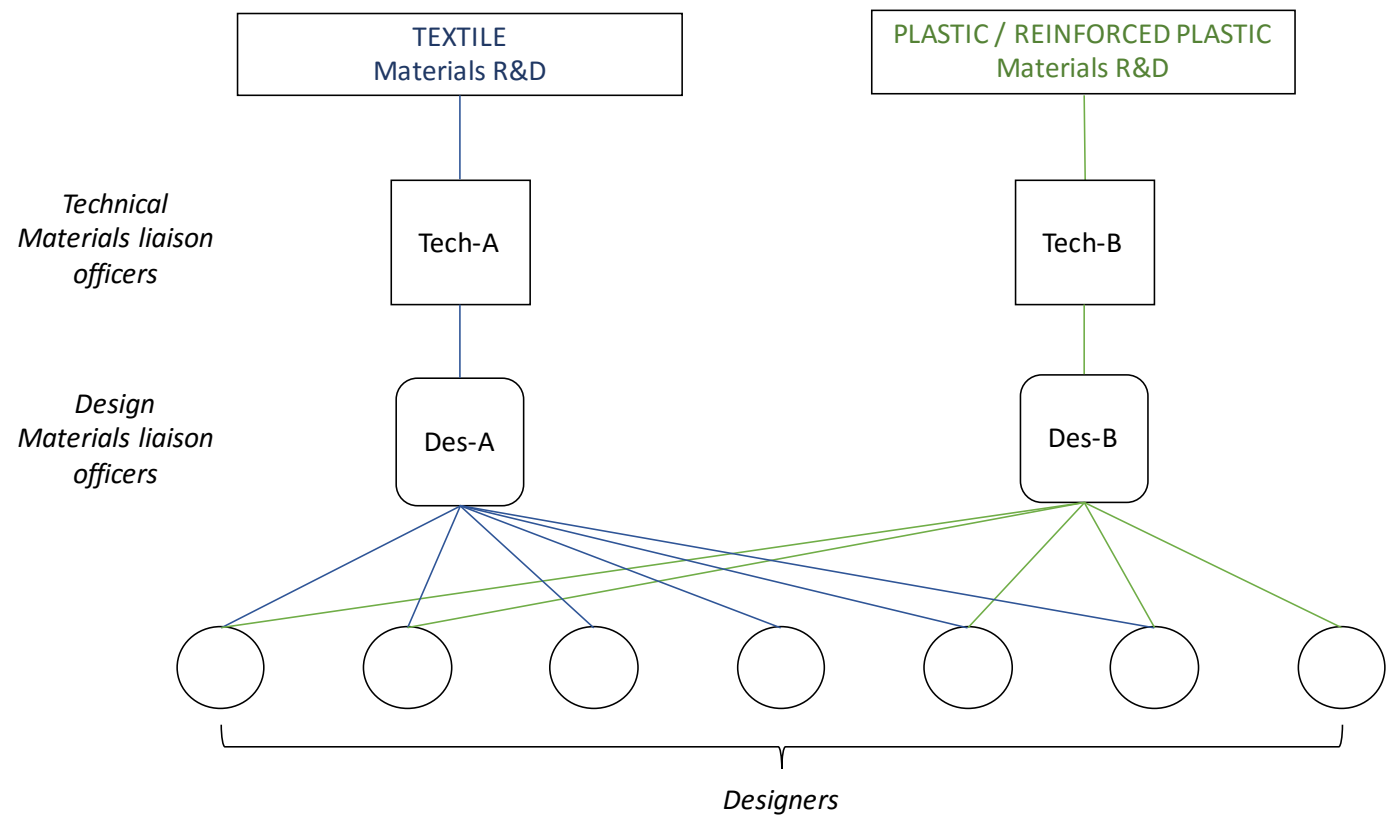

Figure 1: Setting up the dialogue for design-driven materials prototyping via technical and design materials liaison officers

\section{Results}

The results are presented in three sections relating to the key themes. The discussion will then reflect on the implications for materials communication research and practice in relation to DDMI and more generally.

\section{Previous experience}

Appointing MLOs was not a matter of recruiting someone based on an 'ideal' set of skills or experience, but a pragmatic selection of the most appropriate people within the pool of expertise available in the project; best placed in terms of connections, materials knowledge, affiliations and resources (such as project hours and on the right task).

Table 1 presents the background of each MLO in their own words. First, it is striking that all but one person has past experience of translating materials information between different disciplines. Furthermore, all four identify their role as a liaison between the disciplines within the project context and understand the kinds of materials information designers need such as using senseoaesthetic descriptors, 'showing' actual materials (physical or imagery) rather than using technical and quantitative data. This suggests that within industry the role of liaison in materials communication already exists, even if it is not always identified in those terms.

The person with the least experience of communicating with designers [Tech-B] soon recognised the need to communicate 'the advantages' of the materials and 'how they are physically' which is clearly a different type of dialogue than they would normally have with other technical specialists. It would appear that this individual made a transition during the project from being located purely within the technical realm into a position more akin to 'boundary-spanner' (Rieple, Haberberg \& Gander 2005). 
Table 1: The four MLOs' backgrounds as described in the interviews

\begin{tabular}{|c|c|c|c|c|}
\hline $\begin{array}{l}\text { Materials } \\
\text { Liaison } \\
\text { Officer }\end{array}$ & $\begin{array}{l}\text { Disciplinary } \\
\text { background }\end{array}$ & $\begin{array}{l}\text { Has communicated } \\
\text { about materials } \\
\text { with... }\end{array}$ & $\begin{array}{l}\text { Communication role } \\
\text { in current project }\end{array}$ & $\begin{array}{l}\text { Understanding of } \\
\text { interdisciplinary } \\
\text { materials } \\
\text { communication }\end{array}$ \\
\hline Tech-A & $\begin{array}{l}\text { Aerospace engineer, } \\
\text { material science, } \\
\text { specifically lightweight } \\
\text { materials } \\
5-6 \text { years in fibre-based } \\
\text { textiles }\end{array}$ & $\begin{array}{l}\text { Designers } \\
\text { Manufacturers } \\
\text { Other scientists and } \\
\text { engineers }\end{array}$ & $\begin{array}{l}\text { "A sort of linking } \\
\text { between what is the } \\
\text { design and what is the } \\
\text { manufacture on big } \\
\text { volume" }\end{array}$ & $\begin{array}{l}\text { "You need to describe } \\
\text { the materials in terms of } \\
\text { how soft they need to } \\
\text { be, how flexible they } \\
\text { need to be, in } \\
\text { comparison with other } \\
\text { material. They don't } \\
\text { want to have data in } \\
\text { megapascal or } \\
\text { something like this" }\end{array}$ \\
\hline Tech-B & Engineer in chemistry & $\begin{array}{l}\text { Other chemists and } \\
\text { engineers }\end{array}$ & $\begin{array}{l}\text { "To help to } \\
\text { communicate between } \\
\text { different work packages, } \\
\text { to translate information } \\
\text { from [design] work } \\
\text { package to } \\
\text { [prototyping] work } \\
\text { package" }\end{array}$ & $\begin{array}{l}\text { "I realised that designers } \\
\text { didn't know what } \\
\text { reinforced plastics are, } \\
\text { so during the following } \\
\text { workshops I tried to } \\
\text { understand them what } \\
\text { they are, the } \\
\text { advantages, how they } \\
\text { are physically" }\end{array}$ \\
\hline Des-A & $\begin{array}{l}\text { Doctor of Science in } \\
\text { Materials but especially } \\
\text { fibre textile and clothing } \\
\text { science }\end{array}$ & $\begin{array}{l}\text { Manufacturers } \\
\text { Designers } \\
\text { Marketing } \\
\text { Other textile scientists }\end{array}$ & $\begin{array}{l}\text { "The intermediator } \\
\text { between the design and } \\
\text { science, or design and } \\
\text { engineers, because I feel } \\
\text { that I'm standing } \\
\text { somewhere in between } \\
\text { [...] and I think that I can } \\
\text { speak for both } \\
\text { languages, or in both } \\
\text { languages, design and } \\
\text { also science }\end{array}$ & $\begin{array}{l}\text { "The designer cannot } \\
\text { specify what they need } \\
\text { in a quantitative way, so } \\
\text { they can say, yes, a little } \\
\text { bit softer and more matt } \\
\text { or something, and that } \\
\text { is the thing that then I } \\
\text { need to understand } \\
\text { what this is, like, enough } \\
\text { matt" }\end{array}$ \\
\hline Des-B & $\begin{array}{l}\text { Industrial design / } \\
\text { strategy design } \\
\text { consulting related to } \\
\text { materials, use of } \\
\text { material or development } \\
\text { of new material }\end{array}$ & $\begin{array}{l}\text { Scientists, } \\
\text { Material engineers } \\
\text { Companies } \\
\text { Other designers }\end{array}$ & $\begin{array}{l}\text { "facilitator between the } \\
\text { competences involved in } \\
\text { the project [...] the } \\
\text { dialogue among the } \\
\text { competences" }\end{array}$ & $\begin{array}{l}\text { "If you don't show me } \\
\text { materials as a designer I } \\
\text { have some difficulty to } \\
\text { understand about what } \\
\text { technique you are } \\
\text { talking about" } \\
\text { "the images were really } \\
\text { important because they } \\
\text { gave the idea of what } \\
\text { [the designer] have in } \\
\text { mind" }\end{array}$ \\
\hline
\end{tabular}

\section{Materials Liaison (ML) process: from workshop 05 to workshop 06}

As illustrated in Figure 2, the ML process took place over a period of nine weeks between two project workshops. This involved three general steps: 
1. During workshop 05 materials developers (scientists and manufacturers) presented materials samples to designers.

2. In between the workshops designers developed initial product concepts and provided information to MLOs about the material characteristics they required; MLOs communicated with materials developers who then responded by creating prototypes.

3. During workshop 06 materials developers presented the new material prototype samples to designers.

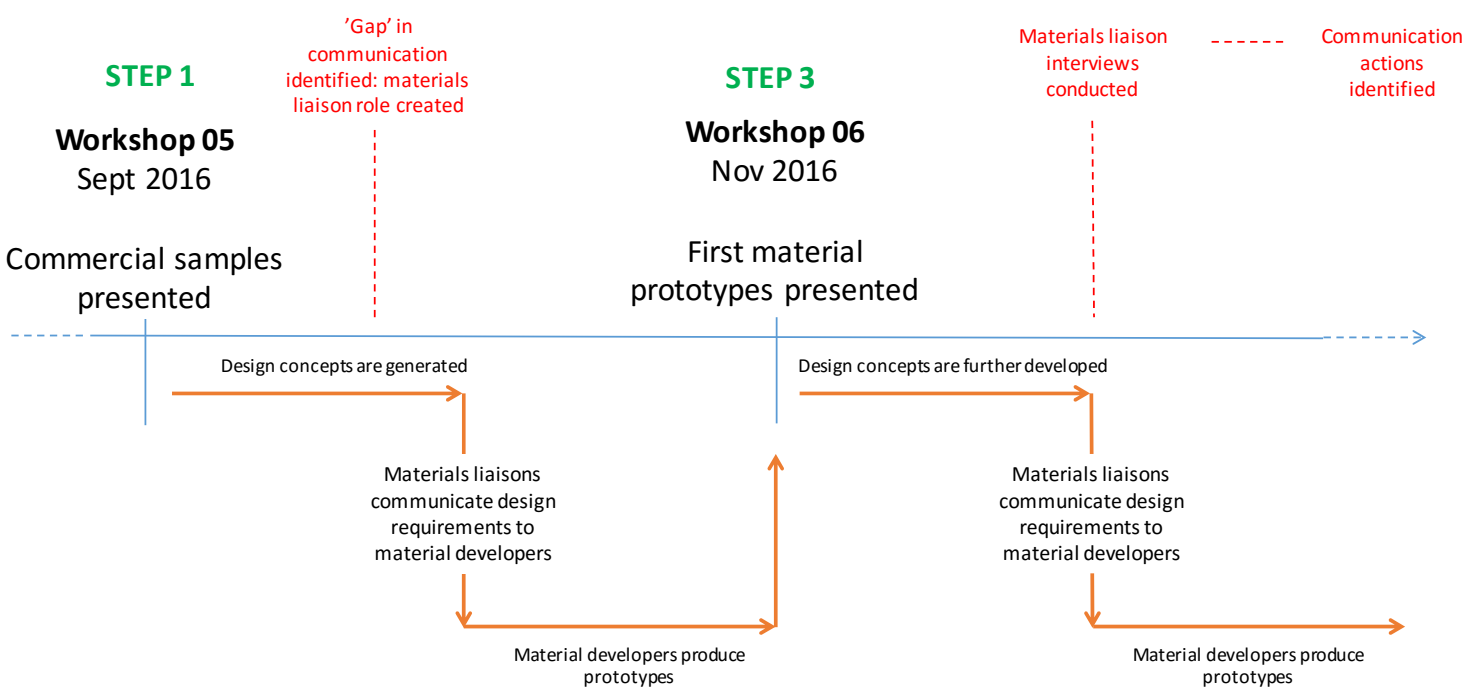

STEP 2

Figure 1: The focus of the study - the ML process - took place over nine weeks between workshop 05 and workshop 06

STEP 1: During workshop 05

The materials presented at workshop 05 were frequently referred to as 'commercial' by the interviewees, to distinguish them from materials that have been produced in the project. The purpose of showing these samples to designers appeared to be both for inspiration as well as to show them the potential of the materials:

"We tried to bring something that have another type of interpretation of material, for example, we brought some sort of foam made of polyester, because it's interesting also to see how it's possible to have this typology of material." [Tech-A]

"the idea was to show to the designers mainly, what we can produce in terms of rigidity, flexibility, and so on" [Tech-B]

"[designers] could get, like, better understanding what kind of possibilities we have in the project" [Des-A]

"what they showed me first of all was the potential, the quality, that could be achieved with that kind of technology that the partner makes available, [...] and also open the mind to, okay, what happens if you include these or we change these - was very inspiring." [Des-B]

STEP 2: In between the workshops 
The process of communication from designers to design MLOs to technical MLOs and then to materials $R \& D$ (refer to figure 1) took place in between the workshops and appeared to offer a good solution to enabling design to drive the materials prototyping:

"Based on this design concept, this table that [Des-B] sent to us, first we tried to understand the concept and then we manufactured some samples [...] We manufactured these samples to discuss with the designers if it's what they were looking for or, yes, to communicate. To understand, to define better the concept." [Tech-A]

"the liaison officers were, like, a nice step to get, let's say, construction or some relevant order to that whole system, how we can go further, [...] that was the one thing which is important, that there are some people who are responsible for something, that those people are named" [Des-A]

However, there was also some difference in opinion about how much influence the liaisons should have over the materials characteristics that are communicated to R\&D with some preferring a completely unbiased approach while one MLO in particular was more involved in deciding and determining the direction of materials R\&D:

"try to put on the paper some description, simply ... not technical, some description about what is the idea of the material you would like to have. After, try to, with the help of a manufacturer, to transform this description in more technical data on which it's possible to work, on which is possible to work to realise the prototypes. Otherwise, these prototypes are simply the choice of singular people" [Tech-A]

The interviews also revealed some issues relating to the diffuse nature of large consortium projects where it is more difficult to be "very linked up, all the day together. In a way that these people already have a language by which it's very easy to shape all the attributes that you want" [Tech-A]; where a lack of close proximity to one another makes materials communication and the ability to understand the potential of the material more difficult.

\section{STEP 3: During workshop 06}

At the workshop scientists and manufacturers (materials R\&D) presented the materials they had produced as a result of the ML process. The MLOs were asked about how these materials differed from those presented at workshop 05. Interviewees described these samples as 'prototypes' to distinguish them as materials produced in the project rather than 'commercial' materials.

The prototypes of the two material typologies (textiles and reinforced plastics) revealed a significant difference in the way that the materials developers were able to respond to the process; a tangible sample of reinforced plastic was produced, whereas only the fibre and finishes (demonstrated on a commercial textile) was produced for textiles:

"the [textile] prototype [in workshop 06] was not considered in terms of fabric from stable fibres, there was totally a gap, you know. There was the Prototype 1 that was stable fibre, and then there was the finishing technology." [Des-B]

This could be because there are a larger number of steps in the production of a textile (and consequently more companies involved), compared to only one or two involved in the production of reinforced plastic. Interviewees noticed that this led to reinforced plastic prototypes that responded more directly to the design concepts within the given timeframe:

"There was really a clear tentative to respond to the designer request, expectation" [Des-B]

"I was really surprised that these composites can be so, like, flexible and even like garment-like, [...] Because that is like a totally different material, what garment industry 
doesn't use usually, so it's like something new way to make the garment material." [Des-A]

There is a further suggestion in this comment that the collaboration had led to a 'surprising' discovery; perhaps the first demonstration of the potential for design to guide the material development in a different direction. This was echoed by the technical MLO responsible for that material prototype:

"Some of [the prototypes] are totally different - Mainly the [design] concepts based on flexible reinforced plastics. The rigid reinforced plastic, well, they are very similar to other samples that we produce in other projects, but the flexible samples, for us it's the first time that we prepare something like this." [Tech-A]

\section{Tools and methods}

The MLOs took different approaches to facilitate the materials communication between the two workshops. As most of the collaborators are based in different European countries, there was no opportunity for face-to-face contact in between the workshops, so communication was conducted via teleconferencing (skype) and by email. Interviewees all felt that these methods were satisfactory in this context. One MLO used the existing design worksheets, which had images and text-based information about the product concept to communicate the design request to materials R\&D. While another created a detailed spreadsheet for designers to fill out with the type of information materials $R \& D$ required.

"the first need that was really clear was to systematise the design concept in clear request, and also understand what kind of requests the technological side needs to realise the prototypes [...] or at least, try to understand what the designer had in mind." [Des-B]

However, when interviewed the MLOs all stated that the most useful type of information provided were images of the product concept and a short description. It is perhaps not surprising that this type of information would be suited to designers but the technical MLOs also said that this helped them to "identify the general idea" [Tech-B]. In the absence of property data, the visual information was a good enough substitute for technical MLOs to interpret what the material needed to be like in terms of senseoaesthetic characteristics for this first iteration of prototyping:

"I noticed that, for example, that [designer] didn't choose specific images and [technical liaison] was not clear ... so the images were really important because they gave the idea of what [the designer] have in mind" [Des-B]

The interviews also highlighted two further issues relating to this phase of the project: how different types of designers responded to the process and the level of design information available at this early stage of DDMI.

Two of the MLO's noted that some designers were more able to engage with the process than others. This appeared related to the designers' familiarity with the material type being developed. For example, MLOs reported difficulties with a textile designer providing information for a reinforced plastic $[$ Des-B] and an industrial designer for a textile:

"they don't have expertise in textiles or garments or fashion business or supply chain or design or material science, which, let's say, [garment retailer] people have. But on the other hand it's good that sometimes that you are coming like out of scope, let's say, so then you have fresh ideas" [Des-A]

However, these were also the exchanges that resulted in more 'surprising' prototypes, discussed earlier. This implies that even though it is more challenging to accommodate designers with less experience of that material typology, it could be the most important and fruitful exchange for materials innovation, and therefore a dialogue that is worth facilitating. 
The early stages of DDMI also appears to be the most challenging time for interdisciplinary communication. During the first iteration of prototyping, design concepts are not fully developed and therefore information about materials characteristics is limited, and there are only existing 'commercial' materials to use as a reference point for communication:

"it is always when you are making first prototype you need to just, like, imagine and hope and decide something." [Des-A]

"also related to the concreteness of the step in which we are, because we saw some prototypes, we have fibres, we can produce some things, so all stuff are more easy [after the first prototype is produced] The beginning is the very issue in this kind of project" [Des-B]

This highlights the important role of physical materials samples. The interviewees all suggested that as long as people were able to touch samples within the workshops then images of those samples would be sufficient reference in between workshops. However, the availability of prototypes even in the workshops was clearly an issue: "A big problem was that it's not possible to have the prototypes that we would like to show" [Tech-A]. Whether it was simply a problem with coordinating the large number of companies involved (as was the case with textiles) or the inability of companies at the start of the supply chain to produce the right amount or type of material for the next part of the process, or a technical issue to do with capability or availability of equipment. The importance of the prototype for providing something 'real' to feed the next iteration of design work was expressed by the interviewees:

"if you want to have a [DDMI] methodology you need to have materials ... first months you need to start to work with materials." [Tech-A]

"It would be good to have these real [prototype] samples that everyone had those, but maybe it's not possible if we don't have, let's say, enough material, but it should be aimed that we can, with all partners, at least designers to have the samples, material samples we have made, all the time, of course, and with the technical specifications." [Des-A]

One MLO suggested that a solution, if properly organised and facilitated, would be to use commercial materials samples to create an 'internal reference'

"the material I think is the best tools to communicate what you have in mind, attributes, properties, [...] I think that talking all the time about these samples, the selected one, the changed one, we can easily refer to them, and if we were able to go ahead, attaching information, let's say, to the photos of these samples [...] create internal references, internal materials, and these references of concrete material that you can touch every time that we meet" [Des-B]

Materials samples are well understood in the literature to be the best way for materials developers to communicate material characteristics to designers. However, the ML process suggests that materials samples could also be very useful to communicate in the other direction, for designers to show materials developers what they would like to achieve, as a comparison:

"Yes, so I asked [the designer] if she could obtain a sample because for us it's very important. It helps us a lot to have something similar to understand better [Tech-B]."

\section{Discussion}

\section{The role of liaisons in interdisciplinary materials communication}

Each Materials Liaison Officer (MLO) had a different level of familiarity with the material they were responsible for communicating and coordinating. In one case the MLO had worked for many years 
specifying the material they were responsible for while another had only a general knowledge of the material.

Not surprisingly, prior knowledge helped the MLOs to communicate the desired materials characteristics more easily. When prior knowledge was limited the liaison used tools and methods to communicate between the two disciplines. Both design and technical MLOs identified images of the design concepts as the most useful medium for understanding what design wanted the materials to do; it enabled them to imagine what the material should be like. Whereas specific information about material thickness and rigidity was more difficult for designers to provide at this early stage in the design process.

This difference exposed the effect that prior knowledge and familiarity can have on the ability to innovate. For example; where prior knowledge was greater this allowed for very easy communication but the request to materials R\&D was almost pre-determined allowing for very little opportunity to challenge conventional specifications. Indeed, the main 'surprise' in terms of materials prototyping both for the design and technical MLOs occurred when design concepts from one industry (textile-garments) informed prototype development in another (reinforced plastics aerospace). Hence less prior knowledge of the material type appeared to be leading towards to a more radical material innovation than greater prior knowledge. Greater familiarity with the material would also appear to put the MLO in a position of influence over the direction of materials R\&D and this could compromise their impartiality when communicating the designers' requests.

Therefore, there appears to be a balance to be reached in terms of the prior knowledge of the material typology being communicated; knowledge needs to be enough for the liaison to have the language to communicate the potential of the material to designers and also translate the design request into useful information for materials $R \& D$, but not so much prior knowledge that it influences their ability to challenge conventional processes or remain impartial.

The interviewees' previous experience and understanding of the role of a 'materials liaison' indicates that this skillset already exists within industry, yet this role is not explicitly named and no support exists for training or placing people with the right skillset within materials innovation contexts. It may be valuable to recognize the MLO role and its potential for enabling interdisciplinary materials communication. This study suggests that with the right experiences and training, people located either in design or materials R\&D could transition into this role so that they are able to bridge disciplinary and communication barriers.

\section{The role of 'commercial' material samples and prototypes}

Within the current project three different typologies of material are under development, although only two were being prototyped during the timeframe of the study: textiles and reinforced plastics. During the ML process these two materials presented very different challenges; namely the number of processes involved; the consequential number of people to liaise / collaborate with (gatekeepers to knowledge); the number of variables that may affect materials characteristics; and, the speed with which prototypes can be produced. Reinforced plastics for example, which in this project were mainly being created for aesthetic purposes rather than for mechanical performance, require only one or two processes. The production of textiles, by comparison, consists of around five different processes (fibre generation, yarn spinning, textile structure, aesthetic finishing, functional finishing) each being performed by a different company. A change to any of these processes can result a change in the characteristics of the finished material. This means that the liaison needs a general knowledge of the processes involved and what can be achieved at each stage as well as the ability to communicate with a number of different material developers. The pace of prototype production is also therefore slower and less responsive for textiles than producing a one-step moulded part, and aligning all of those different processes so that one feeds the other is complex and adds another challenge. 
Nevertheless, the study suggests that having materials samples within the project from the outset both commercial and project prototypes - is important, particularly for designers to see the potential of materials R\&D and for materials developers to get an idea of 'what designers have in mind'. Given the challenge of producing material prototypes and therefore their limited availability, the study suggests that being able to touch the physical materials in the workshop then having images of the prototypes in between workshops as a reference and to aid communication, could be a satisfactory solution. This could also be supplemented with an internal reference collection of commercial materials samples around which an ongoing dialogue can be anchored. Essential to this strategy however, is to 'systematise' the materials so that they are part of an evolving framework relating to the materials $R \& D$, design ideas, interdisciplinary dialogue and decisions. More work needs to be done to create, test and establish such a system.

\section{Creating the conditions for material innovation through cross-fertilisation}

The study has suggested that while it is the more challenging route, enabling designers and materials developers to work across industries could be one way of enabling radical material innovation.

One of the challenges to achieving this is that different types of designers interact with materials in different ways. It is not appropriate to consider 'designer' as one category in the context of DDMI. For example, some designers are 'materials-led' (Karana et al 2015) and develop approaches to materials through hands-on experimentation; it is this experiential understanding of materials that leads the designer to develop new and innovative ways of working with materials. Other designers who are more 'product or function-led' such as industrial designers, are used to 'specifying' materials that are appropriate for their designs with a more distant relationship with materials. The latter are likely to have a general knowledge of materials and rely more on the expertise of intermediaries to help guide them towards the most effective materials selection (Author 2013; 2010). With this in mind, the ML approach which is set up to address a gap between designers and materials developers is perhaps best suited to product and function-led designers who are naturally more distant form the material. However, what this then exposes is the limitations of this type of project for designers who innovate through hands-on materials experimentation. It raises the question of whether this 'gap' between design and technical knowledge could be 'closed' in some other way to improve the chances of material innovation and make the most of the opportunity that design intervention early on in the materials R\&D process presents. A closer collaboration between materials-led designers and technical materials developers might achieve more interesting results, as has been the case with many other smaller interdisciplinary design materials R\&D projects (see for example Ellams 2015). In the context of materials-led design, the ML process may be an ineffective substitute for closer collaboration.

\section{Conclusions}

The Materials Liaison process as described in this study, demonstrates one approach to enabling designers and technical specialists to reach a shared understanding of desired characteristics when prototyping materials for the first time. The approach is one which relies on the ability of intermediaries to 'translate' design ideas, the potential of the material and characteristics between disciplines in a boundary-spanning role. The study revealed that these roles and skillsets already exist within industry but more could be done to support people in the transition from their own discipline into the position of a 'materials liaison', for example through training or interdisciplinary experiences. Placing more people with this skillset, and the right framework for 'acting' out their role, within materials innovation projects would help to support effective collaboration.

However, this approach also has limitations; it requires someone who is sufficiently familiar with the material typology and production process to communicate effectively, but not so involved that they influence the translation process with predetermined ideas. The study has also suggested that the ML process may not be an effective substitute for closer collaboration between materials-led designers and materials R\&D. Finally, the implication is that this process would be most effective 
when an ongoing dialogue is supported by a system of commercial materials samples and material prototypes, and importantly when the aim is to facilitate cross-industry collaboration which appears more likely to result in radical materials innovation.

Interdisciplinary materials communication, while challenging, will be increasingly important as a greater diversity of disciplines are needed to develop innovative, marketable and sustainable new materials. Moreover, this approach has implications beyond materials development. Faced with an increasingly complex problem landscape, designers will need to work with other disciplines. Having a named person to facilitate the interdisciplinary dialogue could be a way of enabling collaboration, especially when working for the first time with limited face-to-face contact. More research needs to be carried out to define these roles and develop the necessary tools and methods to support them.

Within the current project, the research is ongoing; designers, scientists and manufacturers will be interviewed in early 2018 to reflect on their experiences of the whole project, which will be an opportunity to critique and review the findings reported here.

\section{References}

M. Ashby, K. Johnson (2002) Materials and Design: The Art and Science of Material Selection in Product Design Butterworth Heinemann, Oxford

Ellams, D., (2015). 'Colouring Outside the Lines; A cyclical design approach to sustainable coloured fashion \& textiles', Futurescan 3: Intersecting Identities, Glasgow School of Art, 11th \& 12th November

Karana, E., Barati, B., Rognoli, V., van der Laan, A. Z. (2015) Material Driven Design (MDD) A method to design for material experiences. International Journal of Design vol 9 no. 2 pp 35-54

Karana, E., Pedgley, O. \& Ragnoli, V. (eds.) (2014) Materials Experience: Fundamentals of materials and design. Elsevier, Oxford UK.

Karana E. (2004) Guidelines for a materials selection source for industrial design activity: a survey on the expectations of Turkish designers. [Masters Thesis], METU, Ankara, Turkey; 2004

E. Karana, P. Hekkert, P. Kandachar Material considerations in product design: a survey on crucial material aspects used by product designers. Mater. Des., 29 (6) (2010), pp. 1081-1089

Institute of Making (2017) Light Touch Matters Course: Design-led Materials Development http://elearning.instituteofmaking.org.uk/design-led-materials-development/overview (accessed 22/09/17)

Manzini, E. (1986) The Material of Invention: Materials and Design. Milano : Arcadia

Pedgley, O.F. (1999) Industrial Designers' Attention to Materials and Manufacturing Processes: Analyses at Macroscopic and Microscopic Levels. [PhD Thesis] Loughborough University

Rieple, A., Haberberg, A. \& Gander, J. (2005) - Hybrid Organisations as a Strategy for Supporting New Product Development|| Design Management Review 16(1), 48-55

S. Star, J. Griesemer. (1989) Institutional ecology, 'translations' and boundary objects: amateurs and professionals in Berkeley's museum of vertebrate zoology, 1907-39 Soc. Stud. Sci., 19 (1989), pp. $387-420$

van Kesteren, I.E.H. (2008) - Product Designers' Information Needs in Materials Selection|| Materials \& Design 29(1), 133-145

Wilkes, S., Wongsriruksa, S., Howes, P., Gamester, R., Witchel, H., Conreen, M., Laughlin, Z. \& Miodownik, M. (2015) Design tools for interdisciplinary translation of material experiences. Journal of Materials \& Design doi:10.1016/j.matdes.2015.04.013

Author, (2013) conference paper 
Author, (2010) doctoral thesis 